\title{
Customer Segmentation and Optimal Insurance Compensation Ratio: Decision-making Analysis in Financial Institutions
}

\author{
Li Zhou and Ning Zhang * \\ School of Management, Minzu University of China,Beijing, China \\ zhangningmuc@163.com
}

\begin{abstract}
Wit the rapidly development of internet and electronic commerce, all kinds of enterprises are experiencing profound changes. In this paper, we make empirical analysis about insurance decision-making in financial institutions, and analyze influential factors based on customer experience. The result shows that speed and quality is the most important factor that will affect consumption decision-making, the coefficient is 0.152 and 0.144; at the same time, consultation and complaint handling speed is also the significant variable, the coefficient is 0.156 and 0.197 , however, these factors are often been ignored. So that, the insurance company should enhance customer service consciousness, optimize customer claims experience and provide convenient, fast claims service.
\end{abstract}

Keywords: Customer segmentation, Decision-making, Financial institutions, Quality management

\section{Introduction}

In recent years, research on the theory of customer relationship management has been paid attention. Because of the information age, the rapid development of Internet and electronic commerce, in the world scope, all kinds of enterprises are experiencing profound changes in. Enterprises are facing the business environment changes, the traditional business model is increasingly challenged, especially the current homogenization of products and services are becoming increasingly significant trend in many industries, and enterprises should establish competitive advantage becomes more difficult [1]. This makes the competition between the enterprises and the business environment has changed a lot, the competition between enterprises gradually from the category of technological competition and product competition in the service focused, customer oriented comprehensive customer relationship management strategy of competition, the competition focus gradually from the product competition to the competition and customer service competition. Customer economy penetrated every corner on the market today, the traditional product, technology and cost competition is undergoing profound changes, the enterprise must from the strategic point of view on how to establish and maintain a good customer relationship, in order to obtain sustainable competitive advantage [2]. Many enterprises, especially USA and other enterprises in the developed countries, the customer resource is the most important resource, the customer relationship management as a magic weapon [3], through the implementation of customer relationship management, enhance the core competitiveness of enterprises, to meet customer demand, improve customer satisfaction and loyalty, improve customer value, maintain long-term good cooperation relationship with the customer, in order to obtain sustainable competitive advantage, realize the sustainable development of enterprises.

Customer relationship management attention to have the following several aspects, the first reason is the competition between the enterprise is more and more intense, forcing enterprises to seek out of the ordinary and inimitable core competitiveness[4-5]. 
Generally speaking, the source of the core competitiveness of enterprises in the enterprise management element allocation, including the internal human resources, capital, equipment, raw materials, technology and other sources of business relationship with suppliers; to; from the relationship with customers, including the relationship between intermediary and final customer. Only when enterprises carry out the scientific management of the relationship, in order to improve its competitiveness, customer relationship management has been put on the agenda, enterprises attach great importance to it. Two is the management of key evolution. In the past decades, the focus of enterprise management experienced three stages, the first stage is the seventy years of the twentieth Century, the product quality and service quality attention to enterprise management, total quality control (TQC) is generally accepted in the world; the second stage is the eighty years of the twentieth Century, the concept and technology of manufacturing resources MRP plans to sweep the tide of informatization, to improve the internal management efficiency, reduce operating costs, has played an important role; the third stage is the ninety years of the twentieth Century, the enterprise found, to obtain new core competitive advantage, must put the research focus from internal to external enterprises, integration of the whole supply chain partnership, therefore, supply chain management SCM became popular. At present, many enterprises to the implementation of customer relationship management, more requirements of enterprises from the management concept of taking product as the center, to customer centered management idea. The three is the development of management theory. Database marketing, relationship marketing, one to one marketing production and the development of the theory of customer relationship management plays an important role in. Research shows that, the loss of customers to reduce 5\%, the enterprise profit will grow 25-85\% [6], McKinsey research thinks, increase customer loyalty is a very important factor to increase the enterprise's value [7], two times the old customer repeat purchase value is equivalent to the value of the purchase of new customers, customer relationship management can help enterprises to maintain a closer relationship with the customers, also become the enterprise value creating an essential link. Four is the technical progress. Computer technology, database technology, network technology, communication technology, data mining, business intelligence technology, knowledge management technology and the workflow management technology fast development, the customer relationship management in the past is very difficult to become a relatively simple process, the relationship between the Internet to build personalized and interactive for the enterprise and the customer provides a convenient tool for low the cost of the information technology revolution, so the enterprise can through interactive media, with single target customers at any time dialogue and exchanges, makes the transfer of mass communication as the characteristics gradually lost its fascination with one-way information, technical progress of enterprises and customers to establish long-term relations to the possible.

\section{Literature Review}

\subsection{Customer Relationship Management (CRM) Literature Review}

Research on the customer can be traced back to 1899 Veblen's consumer psychology treatise as the theory of the leisure class 8]. In twentieth Century thirty years, experts and scholars began to pay attention to the western analysis of empirical data of customer relationship management. Market research was a prelude to customer research, customer research early mainly to the market investigation and research, personal psychological factors and demographic factors mainly the influence of consumer behavior, take the customer as the center that has been put forward, but the concept of customer relationship management has not been systematically proposed. In twentieth Century fifty years after market products, species increasing and rich, with the development of the market research 
and market research and technological progress, enterprises begin to focus on customer demand. Levitt think, if the enterprise is not to focus on the study of the needs of the market or to understand consumer demand, but only on the product or technology, which will result in loss of competitiveness of enterprise, loss of market, this is the "marketing myopia", he believes that consumer demand is varied, and changing consumer preferences, in different products or services, products just meet a media consumption need, if new products can better meet the needs of the consumer, can not meet the market demand for existing products will be eliminated by the market. William [9] think life style and concept of value can directly affect people's buying behavior, put forward the "values and way of life" concept. Jack [10] believes that enterprises need through the investigation and study to understand consumer thinks, from the consumer point of view, to find the unique market positioning, so as to occupy a favorable competitive position in the eyes of consumers, this is the positioning theory.

In twentieth Century seventy at the end of the 1960s, scholars began to study focus on customer relationship. Arndt [11] research thinks, the enterprise is not only focus on a one-off transaction, but tend to build long-term relationships with customers and suppliers. Berry [12] pointed out the concept of relationship marketing into relationship marketing, it will be defined as to attract, maintain and strengthen customer relationship. Morgan and Hunt [13] pointed out customer to purchase a product or service is not entirely on the basis of a transaction price, but also consider other factors, such as whether a reliable and stable supply, cooperation failure probability level, production capacity is rich in elasticity, etc.

\subsection{Data Mining Literature Review}

The new field of artificial intelligence that computer technology is expedited by the huge demand, after the emergence of the rapid development of artificial intelligence, the Joint Conference on artificial intelligence in 1989 held in Detroit for the first time on the USA proposed knowledge discovery in databases (Knowledge Discovery in Databases, KDD) this terminology, knowledge discovery in database (KDD) formally published.

Classification from the angle of function, data mining algorithms is often divided into four categories, including clustering algorithm, classification algorithm, association analysis algorithm and sequence analysis algorithm. Kaufman [14] first proposed clustering algorithm, they proposed a clustering algorithm of single connection. Alfred [15] provides a general algorithm formula of single connection algorithm. Karypis [16]discussed the clustering algorithm based on graph, also proposed the use of branch and bound thought to expand the exhaustive method to evaluate clustering using range; Zhang [17]proposed for clustering algorithm for large data sets and suing the application of hierarchical clustering algorithm of gene expression data; Kamakura [18] mixing model is studied consumer market modeling and modeling; Aronis developed maximum likelihood classification method; Etzioni and Zamir [19]were designed to study the clustering algorithm of Web documents; Cadez [20]applications in clustering network documentation Markov mixture model is studied.

\subsection{Insurance Data Mining Research}

Data mining technology was first originated in USA in advanced countries, the development of information technology, the insurance industry also have established insurance database system more perfect, the insurance data mining technology research and application in the rapid development of American and European advanced countries, cannot do without data accumulation, technology push and demand pull of three main factors, research on international insurance data 
mining mainly concentrated in two areas, namely, the insurance industry and the insurance industry the possibility of data mining technology in data mining application.

Kietz[21] based on Swiss Life data and using application of OLAP technology, then establish the data warehouse, using data mining methods and carried out empirical research, verify the functions and effectiveness of knowledge of data mining technology in the insurance industry found effective methods, and draw the conclusion data mining is the improvement of the insurance company business operation process; Staudt [22]considers data homogenization processing and information extraction is to use data mining has two key factors, he pointed out that the insurance company has accumulated a large number of customer data, product data, underwriting, claims and investment data, it will improve the insurance company management and application of data mining technology, is not only necessary but also may, a machine learning theory based on theory and data expression, Staudt [23]also makes an empirical research on the extraction of data and information from relational database; Inna and Richard [24]demonstrates how to use data mining technology to insurance risk modeling, and Empirical Study of the cost of health insurance hospital staff pension for predictive modeling and risk modeling.

\section{Questionnaire and Model Design}

\subsection{Questionnaire Survey}

The empirical research uses the method of questionnaire investigation to obtain the main contents of the study required, and with individual interviews for car insurance customer questionnaires. The questionnaire included the institute's need of car insurance customer claims service experience, the data mining on the basis of the questionnaire survey data as the customer data, and make the correlation analysis and research. According to previous research on the questionnaire survey, the design thought of this questionnaire is divided into five steps: (1) design several categories according to the existing literature and research; (2) integrate literature and refine each category ; (3) assume the logical relationship existing between variables, then set up related issues; (4) using expert interviews, adoption their opinions and suggestions, then improve the questionnaire; (5) determine the measurement problem for each variable by exploratory factor analysis, and determine the final questionnaire. The idea of questionnaire design come from arranging and analyzing previous literature, it refers to enterprise cooperation between third-party logistics and the B2C business enterprise. We obtains the preliminary questionnaire by summarizing and comparing existing results, then use expert interviews to increase the appropriateness of the questionnaire items.

\subsection{Structure Model}

In customer segmentation structure model, the basic work of data mining method is through analyzing the known data and then summed up a forecast model. The data can be either historical data or exogenous data; exogenous data can be obtained by experimental method and research method. Data mining method of customer segmentation should have the following abilities:

a) The dynamic behavior description

b) The reliability of the data

c) The noise is resistance and time-varying

d) Synthesis of various mining methods

The implementation process of customer segmentation is based on sample learning method. When deicide the marketing strategy of customer relationship 
management, managers often use some description of customer characters, such as "high-income customers", "low-income customers", "trendy customer", "conservative clients", "high risk customer", the main task of customer segmentation is to ensure the corresponding relations between $t$ these concepts and the corresponding customers. Customer data contains several discrete customer attributes and continuous customer attributes, each customer attribute as a dimension, every customer as a bit of space, the enterprise customer database of all customers can constitute a multidimensional space, called the attribute space of customers.

Assume $\mathrm{A}=\{\mathrm{A} 1, \mathrm{~A} 2, \ldots \mathrm{Am}\}$ Is $\mathrm{A}$ set of properties that describe customer characteristics and behavior, these properties can be either continuous attributes or discrete attributes, these attributes form the m-dimensional space $\mathrm{A}$, each customer value determines the position in space $A$. We assume $c \in C$, the value of $c$ in attribute $\mathrm{Ai}$ is $\mathrm{c}[\mathrm{Ai}]$.we use $\mathrm{g}$ as a abstract concept that descript customer, $\mathrm{f}(\mathrm{g})$ is the set of customer. For a set of concepts $\{\mathrm{gi} 1, \mathrm{gi} 2, \ldots \mathrm{gik}\}$, if $\{\mathrm{f}(\mathrm{gi} 1), \mathrm{f}(\mathrm{gi} 2), \ldots \mathrm{f}(\mathrm{gik})\}$ is $\mathrm{k}$ mutually disjoint sets at any moment, and $\mathrm{C}=\mathrm{f}($ gi1 $) \cup \mathrm{f}($ gi 2$) \cup \ldots \cup \mathrm{f}($ gik $)$, then we can get $\mathrm{Gi}=$ gi $1 \wedge$ gi $2 \wedge \ldots \wedge$ gik. According to $\forall \mathrm{c} \in \mathrm{C}$, if $\mathrm{c} \in \mathrm{f}($ gij $)$ and $1 \leq \mathrm{j} \leq \mathrm{k}$, it can be recorded as $\varphi(\mathrm{c}, \mathrm{Gi})=$ gij. In the concept of customer value dimensions, there are three concepts as "valued customer", "potential value customer", "no value customers", these three concepts can summarize all customers.

We assume $B \subseteq G, R B \subseteq C \otimes C$ is a binary relation of $C$, and $C \otimes C$ is a Cartesian product of $\mathrm{C}$, the formula of $\mathrm{RB}$ is:

$$
R_{B}=\left\{\left(c_{1}, c_{2}\right) \mid c_{1}, c_{2} \in C, \forall b \in B, \varphi\left[c_{1}, b=\varphi\left(c_{2}, b\right)\right]\right\}
$$

In this formula, $\mathrm{RB}$ is an equivalence relation, customers can be divided into several class of the space, and each equivalence class is called a concept class. Customer segmentation is the process that built the mapping relationship of customer attribute space Am and concept space Gn as: Am $\rightarrow$ Gn.The sampler learning method is mainly through data mining process about the customer data, this data mining process was shown as Figure 2. We assume $B=\{$ Gi1, Gi2, . Gik $\}$, so that $\mathrm{L}=\{\mathrm{L} 1, \mathrm{~L} 2, \ldots \mathrm{Lk}\}, \mathrm{c} \in \mathrm{C}$. $\mathrm{c}$ is the customer set that concept class has been known, customer segmentation should fellow two steps as:

a) Define a mapping as p: $\mathrm{C} \rightarrow \mathrm{L}$, which makes $\forall \mathrm{c} \in \mathrm{C}$, if $\mathrm{c} \in \mathrm{Li}$, so $\mathrm{p}(\mathrm{c})=\mathrm{Li}$;

b) $\forall \mathrm{c} \in \mathrm{C}$, determine the class by calculate $\mathrm{p}(\mathrm{c})$.

\subsection{Factors Description}

Through the analysis of the insurance company business requirements, determine the data mining task, specifically the analysis concerned factors on auto insurance customer insurance claims and calculate the influence weight, we summed up the following factors, such as shown in table 1. Factor evaluation insurance claims services research insurance customers, thereby mining key risks insurance claims the improvement point, put forward the concrete policy recommendations to improve business efficiency, insurance claims in insurance claims service, enhance customer satisfaction and loyalty.

Table 1. Description of Factors

\begin{tabular}{|c|c|}
\hline Code & Description of factors \\
\hline $\mathrm{X} 1$ & $\begin{array}{c}\begin{array}{l}\text { You can easily learn how to deal with claims from a variety of sources } \\
\text { formalities }\end{array}\end{array}$ \\
\hline $\mathrm{X} 2$ & The adjustment process, the service personnel to be polite, positive attitude \\
\hline $\mathrm{X} 3$ & Survey personnel can promptly rushed to the scene of the accident, to help you \\
\hline
\end{tabular}




\begin{tabular}{|c|c|}
\hline & deal with on-site \\
\hline X4 & $\begin{array}{c}\text { In the adjustment process, in case you any questions and request, can service } \\
\text { personnel high degree of attention }\end{array}$ \\
\hline X5 & $\begin{array}{c}\text { Even if you don't know about claims service process, service personnel can also } \\
\text { be tolerance, patience explanation }\end{array}$ \\
\hline X6 & Claims, service personnel can accurately, providing professional services \\
\hline X7 & $\begin{array}{c}\text { Insurance company provides a variety of vehicle repair mode, you can always } \\
\text { autonomy to choose according to their own situation }\end{array}$ \\
\hline X8 & You can easily through the website, telephone, query claim progress. \\
\hline X9 & The claims process is relatively smooth, soon to complete the claim \\
\hline X10 & The insurance company can always fulfilled before the service commitment \\
\hline X11 & Any questions or complaints about you, can receive timely treatment \\
\hline X12 & $\begin{array}{c}\text { The overall point of view, the insurance company claims service experience is } \\
\text { better }\end{array}$ \\
\hline
\end{tabular}

\section{Results and Discussion}

In China, insurance has been the main business of property insurance companies, accounted for more than the general reached about $70 \%$, more property insurance company insurance accounted for $90 \%$. The auto insurance business is heavily dependent on the service claims, however, the insurance company insurance business a long time formed heavy business scale, light claims service business ideas, and seriously affect the quality of the insurance services, insurance claims are the masses of the insurance industry, the biggest complaint opinion most field. In recent years, the insurance supervision and Management Committee in the constant introduction of regulations, efforts to improve the efficiency of insurance claims, improve the transparency of insurance work, the insurance industry service claims that there had been some improvement, but from the customer expectations and social identity level there is a huge gap. All insurance companies, especially emerging property insurance companies, such as to attract new customers, retain old customers, must form the characteristic, therefore in the settlement services, the application of scientific methods, study on the effect of insurance customer experience, find the key insurance claims work improved, thus put forward the improvement policy effectively, can efficiently improve the insurance claims service levels, improve customer satisfaction and loyalty.

\subsection{Exploratory Factor Analysis}

First of all, we make exploratory factor analysis for these twelve factors in all the surveyed the client survey data, were preliminary factor analysis according to the A, B two types of customers, to get A, B two kinds of client rotated factor loading matrix in Table 2

Table 2. Rotated Factor Loading Matrix Table

\begin{tabular}{|c|c|c|c|c|c|c|c|}
\hline \multicolumn{3}{|c|}{ Class A good experience } & \multicolumn{5}{c|}{ Class B bad experience } \\
\hline Factors & F1(50\%) & F2(9\%) & Factors & F1(49\%) & F 2(9\%) & F3(7\%) & F4(7\%) \\
\hline X4 & 0.79 & 0.17 & X2 & 0.75 & 0.05 & 0.16 & -0.01 \\
\hline X5 & 0.74 & 0.17 & X6 & 0.09 & 0.11 & 0.26 & 0.25 \\
\hline X6 & 0.7 & 0.36 & X8 & 0.78 & 0.32 & 0 & 0.32 \\
\hline X12 & 0.69 & 0.19 & X5 & 0.77 & 0.25 & 0.29 & -0.02 \\
\hline X8 & 0.67 & 0.28 & X4 & 0.74 & 0.25 & 0.16 & 0.31 \\
\hline X2 & 0.65 & 0.29 & X3 & 0.47 & 0.69 & 0.2 & 0.08 \\
\hline X11 & 0.65 & 0.24 & X11 & 0.14 & 0.89 & 0.07 & 0.07 \\
\hline
\end{tabular}




\begin{tabular}{|c|c|c|c|c|c|c|c|}
\hline $\mathrm{X} 1$ & 0.59 & 0.34 & $\mathrm{X} 7$ & 0.21 & 0.66 & 0.32 & 0.35 \\
\hline $\mathrm{X} 10$ & 0.55 & 0.34 & $\mathrm{X} 9$ & 0.35 & 0.13 & 0.76 & 0.16 \\
\hline $\mathrm{X} 3$ & 0.51 & 0.47 & $\mathrm{X} 1$ & 0.37 & 0.16 & 0.51 & 0.38 \\
\hline $\mathrm{X} 7$ & 0.27 & 0.69 & $\mathrm{X} 10$ & 0.09 & 0.09 & 0.04 & 0.88 \\
\hline $\mathrm{X} 4$ & 0.18 & 0.8 & $\mathrm{X} 12$ & 0.29 & 0.32 & 0.39 & 0.53 \\
\hline
\end{tabular}

\subsection{Factor Analysis Model}

Using the factor analysis method, we get the B type of customer claims experience factor variance decomposition extract principal components analysis table respectively, as shown in table 3 , and the initial factor loading matrix as shown in table 4 . From the cumulative explanation ability as Cumulative\%, we can get that total explanation ability reaches $71.534 \%$, the explanation of the model capacity of more than $60 \%$, the scale has good reliability and validity, so B bad customer experience should be as the key data mining objects, the four principal components were extracted based on the variable can be instead of the original factors.

Table 3. Total Variance Explained

\begin{tabular}{|c|c|c|c|}
\hline principal component & \multicolumn{3}{|c|}{ Extraction Sums of Squared Loadings } \\
\hline & Total & \% of Variance & Cumulative \% \\
\hline 1 & 7.269 & 48.991 & 48.991 \\
\hline 2 & 1.341 & 8.939 & 57.930 \\
\hline 3 & 1.032 & 6.882 & 64.813 \\
\hline 4 & 1.008 & 6.722 & 71.534 \\
\hline
\end{tabular}

Table 4. Component Matrix

\begin{tabular}{|c|c|c|c|c|}
\hline \multirow{2}{*}{ factor } & \multicolumn{4}{|c|}{ Component } \\
\cline { 2 - 5 } & 1 & 2 & 3 & 4 \\
\hline $\mathrm{X} 1$ & .609 & -.248 & .512 & -.257 \\
\hline $\mathrm{X} 2$ & .729 & -.464 & .026 & .129 \\
\hline $\mathrm{X} 3$ & .761 & -.178 & -.072 & -.112 \\
\hline $\mathrm{X} 4$ & .807 & -.105 & -.166 & .215 \\
\hline $\mathrm{X} 5$ & .782 & -.351 & -.063 & -.028 \\
\hline $\mathrm{X} 6$ & .808 & -.241 & -.041 & .256 \\
\hline $\mathrm{X} 7$ & .758 & .077 & -.237 & -.317 \\
\hline $\mathrm{X} 8$ & .558 & .345 & -.343 & -.515 \\
\hline $\mathrm{X} 9$ & .550 & .179 & .576 & -.077 \\
\hline $\mathrm{X} 10$ & .685 & .345 & .130 & .134 \\
\hline $\mathrm{X} 11$ & .746 & .089 & .107 & -.076 \\
\hline $\mathrm{X} 12$ & .389 & .599 & -.032 & .538 \\
\hline
\end{tabular}

Then, we can calculate the four principal component coefficients of each influence factor, divided by the square root of the data principal component characteristic root factor loading matrix of the initial. Four main components are obtained, weighted summary, can get the following comprehensives core model. The comprehensive score model, coefficient of each influence factors is the influence factors explain the ability for comprehensive score, reflects its importance.

\section{$\mathrm{Y}=0.152 \cdot \mathrm{X} 1+0.144 \cdot \mathrm{X} 2+0.156 \cdot \mathrm{X} 3+0.197 \cdot \mathrm{X} 4+0.151 \cdot \mathrm{X} 5+0.198 \cdot \mathrm{X} 6+0.14 \cdot \mathrm{X} 7+0.1$ \\ $78 \cdot \mathrm{X} 8+0.098 \cdot \mathrm{X} 9+0.196 \cdot \mathrm{X} 10+0.224 \cdot \mathrm{X} 11+0.206 \cdot \mathrm{X} 12$}




\subsection{KMO Test}

In order to evaluate the stability of the analysis results, we performed KMO And BArtlett's test, the concrete are presented in Table 5 from the table can be seen, KMO test A, B two kind of customer value was more than 0.9 , belong to "very much" level, strong ability of the interpretation of the results. That our A, B two kinds of the sample of the study and the relationship between the inferences is stable.

Table 5. KMO Test

\begin{tabular}{|c|c|c|c|}
\hline \multirow{4}{*}{$\begin{array}{l}\text { Good customer } \\
\text { experience(A) }\end{array}$} & \multicolumn{2}{|c|}{ KMO Measure of Sampling Adequacy } & .924 \\
\hline & \multirow{3}{*}{$\begin{array}{c}\text { Bartlett's Test of } \\
\text { Sphericity }\end{array}$} & Approx. Chi-Square & 2256.608 \\
\hline & & $\mathrm{df}$ & 105 \\
\hline & & Sig. & .000 \\
\hline \multirow{4}{*}{$\begin{array}{c}\text { Bad experience } \\
\text { customer(B) }\end{array}$} & \multicolumn{2}{|c|}{ KMO Measure of Sampling Adequacy } & .901 \\
\hline & \multirow{3}{*}{$\begin{array}{c}\text { Bartlett's Test of } \\
\text { Sphericity }\end{array}$} & Approx. Chi-Square & 1022.077 \\
\hline & & $\mathrm{df}$ & 105 \\
\hline & & Sig. & .000 \\
\hline
\end{tabular}

\section{Conclusions}

The insurance company leadership and staff have been considered the most important claim is two things: speed and quality. Consultation and complaint handling speed is originally derived work of claims, claims and not the core work, so don't be paid special attention to, generally do not belong to the claims department management, but now it seems, from the customer's claims experience feedback, this work improved demand more urgent than lose the job itself. Customers generally do not have the professional knowledge; the difference is very difficult to distinguish the insurance company to "consultation" and "complaints". Due to the current insurance functions and insurance claims the Advisory complaint handling functions belonging to different sectors, recommend organizational rationalization work, needs to establish a set of effective mechanism to coordinate and solve the insurance customer consultation and complaint handling speed problem.

Customer information database in real time based. But now, the experience from the customer's claim feedback, "convenient inquiry" is still the auto insurance claims and customer experience one of the three major problems to be solved. We have established the customer information infrastructure library, realizes a unified view of customers, therefore suggests that insurance company invested resources, real-time information to upgrade customer base library, fundamentally solve the problem of data query, comprehensive data for customer and customer service personnel to provide convenient, fast, one-stop platform for query. Insurance companies traditionally, auto insurance claims influence customer relationship is the main factor is the speed and quality of claims, claims, and claims quality mainly refers to change policy, whether to allow the claim $4 \mathrm{~S}$ shop repair claims will be damaged, etc. Therefore, the traditional insurance company to concentrate resources devoted to these two aspects. But the research of this project from the customer relationship management efficiency perspective reveals, overall customer pay more attention to communication and pay claims, the requirement of improving the two aspects of the more urgent. Consultation and complaint handling speed and insurance query problem belong to claim the communication problem, therefore, insurance companies will be able to consultation and complaint handling speed boost and insurance claims inquiry re allocation of traditional investment claims and claims of quality work speed part of the incremental resources. 
According to the theory of marginal productivity, carried on a large amount of investment in the field of traditional, its marginal productivity is low, but the traditional rarely put into the field, its marginal productivity is higher, therefore, the incremental resources optimization allocation to the consultation and complaint handling speed boost and insurance query, improve the efficiency of its produce, improve efficiency will be much higher than the claim the speed and quality of claims. This re allocation of incremental resources, customer satisfaction and the insurance company reputation, will be able to improve. But the three part marginal productivity data, unable to get now, so the efficiency of customer relationship management is the source of the upgrade, can not be measured accurately. However, this article only selects the author carried on the test cases in the project customer relationship management of an insurance enterprise, from the perspective of empirical research is not enough, this is the inadequacy of this thesis, also need to continue to further in-depth study and test in the future.

\section{References}

[1] E. Walden and G. J. Browne, "Rational fads in investor reactions to electronic commerce announcements: An explanation of the Internet bubble," Electronic Commerce Research and Applications, vol.7 no.1, (2008).

[2] S. Tak, Y. Lee and E. K. Park, "A software framework for non-repudiation service in electronic commerce based on the Internet," Microprocessors and Microsystems, vol.27 no.5, (2003).

[3] K. Shin and C. S. Leem, "A reference system for internet based inter-enterprise electronic commerce," Journal of Systems and Software, vol.60 no.3, (2002).

[4] D. J. Kim, D. L. Ferrin and H. Rao, "A trust-based consumer decision-making model in electronic commerce: The role of trust, perceived risk, and their antecedents," Decision Support Systems, vol.44 no. 2, (2008).

[5] C. J. Anumba and K. Ruikar, "Electronic commerce in construction-trends and prospects," Automation in Construction, vol.11 no. 3, (2002).

[6] S. Chun and J. Kim, "Pricing strategies in B2C electronic commerce: analytical and empirical approaches," Decision Support Systems, vol.40 no.2, (2005).

[7] K. Hale and R. McNeal, "Technology, politics, and e-commerce: Internet sales tax and interstate cooperation," Government Information Quarterly, vol.28 no.2, (2011).

[8] P. Siriprasoetsin and K. Tuamsuk, "Factors affecting customer relationship management practices in Thai academic libraries," The International Information \& Library Review, vol.43 no.4, (2011).

[9] A. Sen and A. P. Sinha, "IT alignment strategies for customer relationship management," Decision Support Systems, vol.51 no. 3, (2011), pp. 609-619.

[10] Nigel F. P., "Strategic relationships between boundary-spanning functions: Aligning customer relationship management with supplier relationship management," Industrial Marketing Management, vol.38 no.8, (2009).

[11] C. G. R., "Customer Relationship Management (CRM) technology and organizational change: Evidence for the bureaucratic and e-Government paradigms," Government Information Quarterly, vol.28 no.3, (2011).

[12] R. Chalmeta, "Methodology for customer relationship management," Journal of Systems and Software, vol.79 no.7, (2006).

[13] G. Torkzadeh, J. Chang and G. W. Hansen, "Identifying issues in customer relationship management at Merck-Medco,” Decision Support Systems, vol.42 no.2, (2006).

[14] K. Rousseeuw, "Finding Groups in Data: An Introduction to Cluster Analysis," Waley, (1990).

[15] A. Inselberg, "Visualization and Data Mining of High-Dimensional Data," Chemo metrics and Intelligent Laboratory System, vol. 60, (2002).

[16] K. Kumar, "A Parallel Algorithms for Multilevel Graph Partitioning and Sparse Matrix Ordering," Journal of Parallel and Distributed Computing, vol. 48 no.1, (1998).

[17] Z. R. Livny, "Birch: An Efficient Data Clustering Method for Every Large Databases," Data Mining and Knowledge Discovery. vol. 1 no.2,(1997).

[18] W. Kamakura, "Market Segmentation: Conceptual and Methodological Foundations," Kulwer, (1998).

[19] Z. Etzioni, "Web Document Clustering: A Feasibility Demonstration," Proceedings of the 21th International ACM SIGIR Conference. ACM Press, (1998), pp.46-54.

[20] C. Heckerman and M. White, "Visualization of Navigation Pattern on a Web Site Using Model-Based Clustering," Proceedings of the ACM the 7th International Conference on Knowledge Discovery and Data Mining. ACM Press, (2000), pp. 280-284.

[21] M. Kirlidog and C. Asuk, "A Fraud Detection Approach with Data Mining in Health Insurance," Procedia - Social and Behavioral Sciences, vol. 62 no.2, (2012). 
[22] Y. Chae and H. Seung, "Data mining approach to policy analysis in a health insurance domain," International Journal of Medical Informatics, vol. 62 no.2, (2001).

[23] S. Liao, Y. Chen and Y. Tseng, "Mining demand chain knowledge of life insurance market for new product development," Expert Systems with Applications, vol. 36 no.5, (2009).

[24] J. Paefgen and T. Staake, "Evaluation and aggregation of pay-as-you-drive insurance rate factors: A classification analysis approach,” Decision Support Systems, vol. 56, (2013). 